Check for updates

Cite this: RSC Adv., 2019, 9, 25890

\title{
Characterization of the genome from Geobacter anodireducens, a strain with enhanced current production in bioelectrochemical systems $\uparrow$
}

\author{
Dan Sun, (D) *a Xinyuan Wan, ${ }^{\mathrm{a}}$ Wenzong Liu, ${ }^{\mathrm{b}}$ Xue Xia, ${ }^{\mathrm{b}}$ Fangliang Huang, ${ }^{\mathrm{c}}$ Aijie Wang, ${ }^{\text {b }}$ \\ Jessica A. Smith, (D) ${ }^{d}$ Yan Dang ${ }^{e}$ and Dawn E. Holmes ${ }^{f}$
}

Geobacter anodireducens is unique in that it can generate high current densities in bioelectrochemical systems (BES) operating under high salt conditions. This ability is important for the development of BES treating high salt wastewater and microbial desalination cells. Therefore, the genome of $G$. anodireducens was characterized to identify proteins that might allow this strain to survive in high salt BES. Comparison to other Geobacter species revealed that 81 of its 87 c-type cytochromes had homologs in G. soli and G. sulfurreducens. Genes coding for many extracellular electron transfer proteins were also detected, including the outer membrane $c$-type cytochromes OmcS and OmcZ and the soluble c-type cytochrome PgcA. G. anodireducens also appears to have numerous membrane complexes involved in the translocation of protons and sodium ions and channels that provide protection against osmotic shock. In addition, it has more DNA repair genes than most Geobacter species, suggesting that it might be able to more rapidly repair DNA damage caused in high salt and low $\mathrm{pH}$ anode environments. Although this genomic analysis provides invaluable insight into mechanisms used by $G$. anodireducens to survive in high salt BES, genetic, transcriptomic, and proteomic studies will need to be done to validate their roles.

Received 27th March 2019

Accepted 20th July 2019

DOI: $10.1039 /$ c9ra02343g

rsc.li/rsc-advances

\section{Introduction}

Extracellular electron transfer (EET) is an important bioprocess that plays a role in global biogeochemical cycles, bioremediation applications, as well as anaerobic digestion. ${ }^{1}$ EET is primarily carried out by dissimilatory metal-reducing bacteria (DMRB), which have the ability to transfer electrons from the cytoplasm to the outer cell surface in order to reduce extracellular electron acceptors including $\mathrm{Fe}($ III), neighboring

${ }^{a}$ Ocean College, Zhejiang University, Zhoushan 316021, P. R. China. E-mail: dsun@ zju.edu.cn

${ }^{b}$ Key Laboratory of Environmental Biotechnology, Research Center for EcoEnvironmental Sciences, China Academy of Sciences, Beijing 100084, P. R. China. E-mail: ajwang@rcees.ac.cn

${ }^{c}$ College of Life Sciences, Zhejiang University, Hangzhou 310058, P. R. China

${ }^{d}$ Department of Biomolecular Sciences, Central Connecticut State University, 1615 Stanley Street, New Britain, CT 06050, USA

${ }^{e}$ Beijing Key Laboratory for Source Control Technology of Water Pollution, Engineering Research Center for Water Pollution Source Control and Eco-remediation, College of Environmental Science \& Engineering, Beijing Forestry University, 35 Tsinghua East Road, Beijing 100083, China

${ }^{f}$ Department of Physical and Biological Sciences, Western New England University, 1215 Wilbraham Rd, Springfield, MA 01190, USA

$\dagger$ Electronic supplementary information (ESI) available: Supplementary data related to this article can be found in the online version. See DOI: $10.1039 / \mathrm{c} 9 \mathrm{ra02343g}$ microorganisms via direct interspecies electron transfer (DIET), or electrodes in microbial fuel cells (MFCs). ${ }^{2,3}$

MFCs rely on microorganisms that colonize the anode to transfer electrons from the oxidation of organic matter. MFC technology has been developed for a variety of bioelectrochemical system (BES) applications including hydrogen production, ${ }^{4}$ desalination, ${ }^{5}$ organic product synthesis, ${ }^{6}$ biosensors, ${ }^{7-9}$ and wastewater treatment. ${ }^{10}$ The study of EET by exoelectrogens has resulted in the development of the novel sub-discipline, electromicrobiology. ${ }^{11-13}$ However, mechanisms used to transfer electrons from a microorganism's cytoplasm out to extracellular electron acceptors like anodes still remains an area of controversy. Therefore, identification and characterization of microbes that are superior in their EET capabilities is essential for understanding the EET mechanisms favored in the environment and for practical applications.

Mechanisms for EET have been most thoroughly studied in the genera Geobacter and Shewanella. ${ }^{14}$ The model exoelectrogenic Shewanella species, S. oneidensis, uses a single known pathway to transfer electrons from an inner membrane cytochrome (CymA) to the MtrCAB porin-multiheme $c$-type cytochrome complex. ${ }^{15}$ The Mtr proteins directly reduce flavins, which can act as soluble electron shuttles. ${ }^{16}$ Approximately $75 \%$ of EET by $S$. oneidensis results from electron shuttles, which allows it to produce current in MFCs even though it 
cannot form thick biofilms. ${ }^{\mathbf{1 7 - 1 9}}$ Geobacter species, on the other hand, form very thick biofilms, and a recent study showed that G. sulfurreducens produced $1047 \%$ times more maximum current than $S$. oneidensis. ${ }^{20}$

Geobacter spp. are the most abundant microorganisms in anaerobic soils and sediments where microbial reduction of insoluble $\mathrm{Fe}(\mathrm{III})$ oxides is important. ${ }^{1}$ To date, a total of 21 Geobacter species have been characterized (NCBI Taxonomy browser). Nearly all of the research regarding mechanisms of EET by Geobacter has been conducted in G. sulfurreducens strain PCA because it was the first to have a genome sequence, it can be genetically manipulated, and its metabolic traits such as rapid growth with fumarate as the electron acceptor make it easy to cultivate in the lab. ${ }^{21,22}$ However, G. sulfurreducens is not the most environmentally representative strain as it does not reduce $\mathrm{Fe}(\mathrm{III})$ oxides or produce current as effectively as some other Geobacter species ${ }^{23-27}$ and it rarely shows up in environmental samples. ${ }^{3}$

Although it is apparent that Geobacter species do not use soluble flavin shuttles like Shewanella, there does not seem to be one single pathway for EET amongst the genus. All Geobacter genomes sequenced to date appear to have genes that code for abundant multiheme $c$-type cytochromes and electrically conductive type IV pili (e-pili). ${ }^{28-30}$ However, specific mechanisms used for EET seem to vary between species and even among strains of the same species. ${ }^{31-33}$ For example, the soluble extracellular $c$-type cytochrome PgcA is required for $\mathrm{Fe}(\mathrm{III})$ oxide reduction in some strains of G. sulfurreducens ${ }^{\mathbf{3 4}}$ and in the absence of e-pili, ${ }^{32}$ but it is not significant in other strains. ${ }^{35}$ In addition, OmcS facilitates electron transfer to $\mathrm{Fe}(\mathrm{III})$ oxide $^{33}$ and anodes with thin biofilms formed by $G$. sulfurreducens ${ }^{36}$ while a different $c$-type cytochrome, OmcZ, is involved in EET in thick anode biofilms. ${ }^{37,38}$ G. metallireducens does not have OmcS, although several other $c$-type cytochromes as well as e-pili are essential for EET. ${ }^{32,39,40}$ Furthermore, some Geobacter strains that are capable of Fe(III) oxide reduction, are completely incapable of current generation. For example, G. bemidjiensis contains both e-pili and a $c$-type cytochrome in the OmcZ family, however it is not able to produce current. ${ }^{23,41}$

Geobacter anodireducens was the first Geobacter species isolated from an anode biofilm based on its ability to generate current. $^{26}$ In cyclic voltammetry, electrochemical impedance spectroscopy, and biomass tests, G. anodireducens SD-1 performed better than G. sulfurreducens PCA, G. metallireducens GS-15, and a mixed culture (wastewater). Current production was even greater in BESs operating with high salt concentrations. $^{42}$ Geobacter anodireducens SD-1 will be useful for providing additional insights into superior EET mechanisms and current generation in BESs. As more is learned, development of various new BES technologies can emerge. In this study, the genome of $G$. anodireducens SD-1 was analyzed and compared to genomes from closely related Geobacter species that are also able to generate current in MFCs in order to identify genes that might lead to the enhanced EET capabilities of SD-1.

\section{Experimental}

\subsection{Physiological characterization}

Geobacter anodireducens SD-1, Geobacter sulfurreducens PCA (ATCC 51573), and Geobacter metallireducens GS-15 (ATCC 53774) were acquired from Dr Bruce Logan's laboratory culture collection at Pennsylvania State University and grown anaerobically on bicarbonate-buffered medium (BCM-30) ${ }^{43}$ with acetate $\left(1 \mathrm{~g} \mathrm{~L}^{-1}\right)$ provided as the electron donor and $\mathrm{Fe}(\mathrm{III})$ citrate (20 $\mathrm{mM})$ as the electron acceptor. All incubations were conducted under an $80: 20 \mathrm{~N}_{2}: \mathrm{CO}_{2}$ atmosphere at $30{ }^{\circ} \mathrm{C}$ in the dark. $^{26}$

Electrical activities of SD-1, PCA, and GS-15 were tested in mini-BESs $(5 \mathrm{ml})$ with graphite plate anodes and stainless steel mesh cathodes as previously described. ${ }^{\mathbf{4 2 , 4 4}}$ Microbial electrolysis cell (MEC) chambers were filled with either $50 \mathrm{mM}$ phosphate buffer (PBM-50), $200 \mathrm{mM}$ phosphate buffer (PBM-200), or saline water (SW, $50 \mathrm{mM}$ PBS with $3.8 \% \mathrm{NaCl}$ ) and $1 \mathrm{~g} \mathrm{~L}^{-1}$ sodium acetate was provided as the electron donor. Reference electrodes (Ag/AgCl; +200 mV vs. standard hydrogen electrode (SHE); BASi) were used to record anode and cathode potentials. An applied potential of $0.7 \mathrm{~V}$ was supplied to each MEC. MECs were operated with a programmable power supply (model 3645A; Circuit Specialists Inc), and each circuit contained a $10 \Omega$ resistor.

Voltage was recorded at 20 minute intervals with a multimeter (model 2700; Keithley Instruments Inc.), and current was calculated using Ohm's law $(I=V / R)$. Volumetric current density $\left(I_{\mathrm{V}} ; \mathrm{A} \mathrm{m}^{-3}\right)$ was determined by dividing current by liquid volume, and current density per area $\left(I_{\mathrm{A}} ; \mathrm{A} \mathrm{m}^{-2}\right)$ was calculated by dividing current by anode surface area.

$\mathrm{Fe}(\mathrm{III})$ reduction was monitored by measuring $\mathrm{Fe}(\mathrm{II})$ that could be extracted in $0.5 \mathrm{M} \mathrm{HCl}$ after a 1 hour incubation with a ferrozine assay at an absorbance of $562 \mathrm{~nm}$ as previously described..$^{45}$

\subsection{G. anodireducens SD-1 genome sequencing, assembly and annotation}

Total genomic DNA was extracted with a DNA extraction kit (Lifefeng), according to the manufacturer's protocol. The concentration and purity of DNA was measured with a NanoDrop spectrophotometer (ND 1000, Thermo Fisher Scientific, $\mathrm{DE}$ ). The genome of strain $G$. anodireducens SD-1 was sequenced at the Life Science College of Zhejiang University using the PGM system (ABI, USA). The Ion Torrent data included a 350 bp paired-end library and a $3 \mathrm{k}$ bp mate-pair library, and a total of $0.8 \mathrm{G}$ and $0.6 \mathrm{G}$ of raw data were produced after filtering, respectively. These sequences were assembled into 2 contigs using the CLC Genomics Workbench 6.0 (CLCbio, Waltham, MA).

Preliminary annotation was performed using Rapid Annotation Subsystem Technology (RAST) ${ }^{46}$ and NCBI. SignalIP v4.1 was used to identify genes with signal peptides, and THMMER 2.0 was used to define genes with transmembrane helices. ${ }^{47,48}$ Translated amino acids were assigned to Kyoto Encyclopedia of Genes and Genomes (KEGG) pathways using KASS (KEGG Automatic Annotation Server). ${ }^{49}$ 


\subsection{Comparative genomics}

Genomes from Geobacter anodireducens SD-1 (NZ_CP014963 and NZ_CP014964), G. soli GSS01 (NZ_JXBL01000000), G. sulfurreducens PCA (NC_002939), and G. metallireducens GS-15 (NC_007517 and NC_007515) were downloaded from NCBI and screened by comparison to sequences in the NR database with the BLASTp algorithm ${ }^{50}$ using NCBI BLAST-2.2.31+ standalone software. ${ }^{51} C$-type cytochrome proteins were identified by screening each protein for the heme binding motif $(\mathrm{CXXCH})$. Tools on the IMG/M (Integrated Microbial Genomes \& Microbiomes) website (https://img.jgi.doe.gov) were also used for comparison of the four genomes.

\section{Results and discussion}

\subsection{Similarities to Geobacter soli GSS01}

Geobacter anodireducens SD-1 was isolated from a MFC biofilm inoculated with effluent collected from a primary clarifier at the Pennsylvania State University Wastewater Treatment Plant. ${ }^{52}$ Intriguingly, its genome is most similar to another Geobacter species, Geobacter soli GSS01, isolated from a completely different environment. Geobacter soli GSS01 was isolated from a soil sample taken from the humic layer of an underground ancient forest in China. ${ }^{27}$ Comparisons of the two genomes with the Pairwise ANI (ANI; a measure of nucleotide-level genomic similarity between the coding regions of two genomes) tool available on the IMG/MER website (www.img.jgi.org) revealed that $99.64 \%$ of the genes are similar.

The physiologies of $G$. anodireducens and $G$. soli also appear to be quite similar (Table 1). Both strains can couple the oxidation of acetate with a variety of extracellular electron acceptors including Fe(III), $\mathrm{S}^{0}, \mathrm{Mn}(\mathrm{IV})$, and AQDS, and neither strain can respire fumarate. However, G. soli can grow with nitrate provided as an electron acceptor, ${ }^{27}$ while G. anodireducens cannot couple the oxidation of organic compounds with nitrate respiration. ${ }^{\mathbf{2}}$

G. anodireducens and G. soli are both much more similar to G. sulfurreducens than to G. metallireducens. Pairwise ANI values from comparisons of G. anodireducens to G. sulfurreducens and

Table 1 Major physiological characteristics of $G$. anodireducens SD-1 (ref. 26), G. sulfurreducens PCA, ${ }^{25}$ G. metallireducens GS-15 (ref. 55), and G. soli GSSO1 (ref. 27) ${ }^{a}$

\begin{tabular}{lllll}
\hline Characteristic & SD-1 & PCA & GS-15 & GSS01 \\
\hline Acetate (electron donor) & Yes & Yes & Yes & Yes \\
Hydrogen (electron donor) & Yes & Yes & No & ND \\
Ferric citrate (electron acceptor) & Yes & Yes & Yes & Yes \\
Fumarate (electron acceptor) & No & Yes & No & No \\
Nitrate (electron acceptor) & No & No & Yes & Yes \\
Sulfur (electron acceptor) & Yes & Yes & No & Yes \\
Mn(Iv) (electron acceptor) & Yes & Yes & Yes & Yes \\
AQDS (electron acceptor) & Yes & Yes & Yes & Yes \\
MFC anode (electron acceptor) & Yes & Yes & Yes & Yes \\
NaCl tolerance & $3.0 \%$ & $1.7 \%$ & $0.5 \%$ & ND \\
Presence of plasmid & Yes & No & Yes & No
\end{tabular}

${ }^{a}$ ND: not determined.
G. metallireducens were 93.10 and 78.65 , respectively. Similar to most members of the genus Geobacter, all four strains can utilize both soluble and insoluble Fe(III) as the sole electron acceptor coupled with the oxidation of acetate, ${ }^{25-27,53}$ and are capable of producing current on the anode of MFCs (Table 1). ${ }^{11,26,54}$

\subsection{Physiological comparison of Geobacter anodireducens to G. sulfurreducens and G. metallireducens}

Due to the in depth characterization and completed genome sequences of G. sulfurreducens PCA and G. metallireducens GS15 , further physiological comparisons with these species were done in order to uncover potential mechanisms used for enhanced EET in high salinity environments. As previous research has shown, $G$. anodireducens SD-1 grew fastest of the three strains with soluble Fe(III) citrate provided as the electron acceptor. It had a doubling time of only 5.4 hours, while generation times of $G$. metallireducens GS-15 and G. sulfurreducens PCA were only 6.11 and 9.11 hours, respectively (ESI Fig. S1A $\dagger){ }^{26}$ In addition, strain SD-1 consistently produced the highest currents in BES with high-salt solutions (50 or $200 \mathrm{mM}$ phosphate buffer solution, and high salinity water) (ESI Fig. $\mathrm{S} 1 \mathrm{~B} \dagger)^{42}$

Geobacter anodireducens shares some physiological traits with both G. sulfurreducens and G. metallireducens. All three species can grow with a number of insoluble extracellular electron acceptors including current-harvesting anodes, Fe(III), Mn(Iv), and AQDS (Table 1). ${ }^{25,26,35,53}$ However, among the three species only G. anodireducens and G. sulfurreducens can grow with elemental sulfur provided as an electron acceptor. ${ }^{25,26}$ Fumarate is a soluble electron acceptor that can only be used by G. sulfurreducens ${ }^{25}$ while nitrate is a soluble electron acceptor that can only be utilized by $G$. metallireducens. ${ }^{53}$ Another important difference between these strains is that G. anodireducens is much more salt tolerant compared to the other two strains. ${ }^{42}$ Similar to G. metallireducens, a plasmid was identified in the G. anodireducens genome.

In terms of environmental niche, G. anodireducens SD-1 survived at $\mathrm{pH}$ and temperature ranges similar to those of G. metallireducens and G. sulfurreducens. ${ }^{25,26,53}$ However, SD-1 was able to grow with up to $3 \% \mathrm{NaCl}^{26}$ which is significantly higher than $G$. sulfurreducens and $G$. metallireducens which could only tolerate $1.7 \% \mathrm{NaCl}^{25}$ and $0.5 \% \mathrm{NaCl}^{53}$ respectively. Furthermore, SD-1 generated significant current in BES with $200 \mathrm{mM}$ phosphate buffer and $650 \mathrm{mM} \mathrm{NaCl}$, while neither G. sulfurreducens nor G. metallireducens could grow in the high salt solution and both were significantly impaired in $200 \mathrm{mM}$ phosphate solutions (ESI Fig. S1B $\dagger$ ). ${ }^{42}$ Salt concentrations have been shown to influence microbial metabolism in MFCs and a recent study demonstrated that $\mathrm{NaCl}$ concentrations should remain below $0.1 \mathrm{M}$ for optimal electricity generation. ${ }^{55}$ SD-1's ability to withstand such high salt concentrations will make the strain useful in future application of microbial desalination cells and microbial reverse electrodialysis cells ${ }^{56}$ as well as BES used for bioremediation of high salt solutions. ${ }^{57}$ 


\subsection{General genomic features}

The complete genome of SD-1 consists of a circular chromosome of 3555507 bp with a GC content of $61.8 \%$ and a circular plasmid of $110507 \mathrm{bp}$ with a GC content of $52.2 \%$. In total, 3434 genes have been identified on the chromosome and 130 genes have been detected on the plasmid. These genome statistics are similar to those from the G. soli, G. sulfurreducens, and G. metallireducens genomes, except that $G$. metallireducens is the only other species with a plasmid (Table 2).

The Function Category Comparison tool on the IMG/MER website was used to classify genes from various COG pathways in the four different genomes (ESI Table S1 $\dagger$ ). The comparison revealed that both the $G$. anodireducens and $G$. soli genomes have genes coding for two ATP synthase complexes, the F- and V-type ATPases. The only other Geobacter species that have both ATPase complexes are G. uraniireducens and Geobacter sp. M18. ${ }^{58}$ The F-type ATPase complex is found in most bacteria, eukaryotic mitochondria, and chloroplasts ${ }^{58-60}$ while the V-type complex is found in archaea, a few bacteria, and eukaryotic vacuoles. ${ }^{\mathbf{5 , 6 1 - 6 3}}$ Studies have found that both of these ATPases can translocate protons or sodium ions across the membrane to drive the synthesis or hydrolysis of ATP. ${ }^{58,59,63}$ Analysis of subunit $c$ from the F- and V-type ATPase complexes revealed that neither appears to have $\mathrm{Na}^{+}$-binding sites, ${ }^{\mathbf{5 8}}$ suggesting that both of these ATPase complexes are proton-dependent.

Another difference among these genomes is the presence of genes for a multisubunit $\mathrm{NA}^{+} / \mathrm{H}^{+}$antiporter in G. anodireducens, G. soli, and G. sulfurreducens, but not G. metallireducens. There are $7 \mathrm{Mrp}$ (multiple resistance and $\mathrm{pH}$ ) subunits (MrpA-G) required for enzymatic activity ${ }^{\mathbf{6 4}}$ and $G$. anodireducens has genes for all 7 of these subunits (Ga0133348_111263Ga0133348_111270). The Mrp complex is a $\mathrm{Na}^{+} / \mathrm{H}^{+}$antiporter that utilizes the proton motive force to efflux intracellular sodium ions, and its functions include sodium tolerance and pH homeostasis. ${ }^{65-68}$ This complex is likely to be important for the high salt tolerance of $G$. anodireducens. ${ }^{42}$

An additional notable difference is that the number of fatty acid metabolism genes is significantly higher ( $\sim 3$ times) in the G. metallireducens genome than the other three genomes. This can be explained by the fact that $G$. metallireducens is able to utilize a number of aromatic hydrocarbons (i.e. benzoate, toluene, phenol, $p$-cresol, benzene) as electron donors ${ }^{53,69}$ and these pathways share many genes with the fatty acid degradation pathway. ${ }^{70-72}$

Table 2 Basic genome statistics from $G$. anodireducens SD-1, G. soli GSS01, G. sulfurreducens PCA, and G. metallireducens GS-15

\begin{tabular}{llcl}
\hline & $\begin{array}{l}\text { Total number } \\
\text { of bases }\end{array}$ & $\begin{array}{l}\text { Number of } \\
\text { genes }\end{array}$ & \% G + C \\
\hline SD-1 chromosome & 3555507 & 3434 & $61.8 \%$ \\
SD-1 plasmid & 110507 & 130 & $52.2 \%$ \\
GSS01 chromosome & 3657100 & 3388 & $61.8 \%$ \\
PCA chromosome & 3814128 & 3711 & $60.9 \%$ \\
GS-15 chromosome & 3997420 & 3617 & $59.5 \%$ \\
GS-15 plasmid & 13762 & 18 & $52.5 \%$
\end{tabular}

\subsection{Metabolic pathways}

All four Geobacter species have genes coding for all of the enzymes in the tricarboxylic acid (TCA) cycle (Fig. 1). The $G$. metallireducens genome, however, has significantly more TCA cycle genes (ESI Table S1 $\dagger$ ), as it has multiple copies of many of the enzymes. For example, G. metallireducens has two citrate synthase ( $g l t A)$ genes and two sets of genes coding for the succinate dehydrogenase/fumarate reductase complex. ${ }^{24}$

Similar to $G$. metallireducens, neither $G$. anodireducens nor $G$. soli are capable of growth with fumarate provided as the electron acceptor. ${ }^{26,27}$ Both of these organisms have genes that code for a succinate dehydrogenase complex which also functions as a respiratory fumarate reductase in G. sulfurreducens; Ga0133348_112411-112413 in G. anodireducens and Ga0077628_111869-111871 in G. soli (Fig. 2). However, their genomes lack the gene that codes for the anaerobic C4dicarboxylate transporter $(d c u B)$, which is required for the transport of aspartate, malate, fumarate, and succinate by many bacterial species. ${ }^{73-75}$ When the $d c u B$ gene from $G$. sulfurreducens is expressed on a vector introduced into G. metallireducens, fumarate respiration is possible. ${ }^{76}$ It is likely that both of these strains would also be able to respire fumarate if the G. sulfurreducens $d c u B$ gene was introduced into their chromosomes.

The respiratory nitrate reduction pathway has been characterized in G. metallireducens and genes for the nitrate reductase complex (narGYJI) and the nitrate/nitrite antiporter (narK) have been identified. ${ }^{24}$ Analysis of the other three genomes did not reveal the presence of any genes that code for proteins involved in nitrate respiration. This is consistent with the fact that neither G. sulfurreducens nor G. anodireducens can grow with nitrate provided as an electron acceptor. However, it is interesting that $G$. soli was reported to grow with nitrate provided as the sole electron acceptor. ${ }^{27}$ Further investigation into the mechanism for nitrate reduction used by $G$. soli is required.

\subsection{Electron transport genes involved in extracellular electron transfer}

Similar to other characterized Geobacter species, G. anodireducens appears to excel at its ability to exchange electrons with the extracellular environment. ${ }^{26}$ Numerous studies have identified $c$-type cytochromes that are involved in extracellular electron transfer to or from such substrates as Fe(III) oxide, $\mathrm{Fe}(\mathrm{III})$ citrate, Mn(Iv) oxide, electrodes, $\mathrm{Fe}(0), \mathrm{Fe}(\mathrm{III})$ containing sediments, and other microorganisms in such organisms as $G$. sulfurreducens, ${ }^{33,37,77-79}$ G. metallireducens, ${ }^{32,40}$ G. soli, ${ }^{54}$ and $G$. uraniireducens. ${ }^{35}$

The G. anodireducens genome has 87 genes that could potentially code for $c$-type cytochrome proteins (ESI Table S2 $\dagger$ ). Four of these cytochromes are predicted to be localized to the inner membrane, 24 are extracellular or outer membrane associated, and 24 are periplasmic. More than half $(53.5 \%)$ of these $c$-type cytochromes have 5 or more heme groups and $30.2 \%$ have 2 to 4 hemes. Many of these $c$-type cytochromes have homologs in both G. soli and G. sulfurreducens (ESI Table S2A $\dagger$ ). In addition, many of the $c$-type cytochromes that genetic, transcriptomic, proteomic, and genomic studies have identified as 


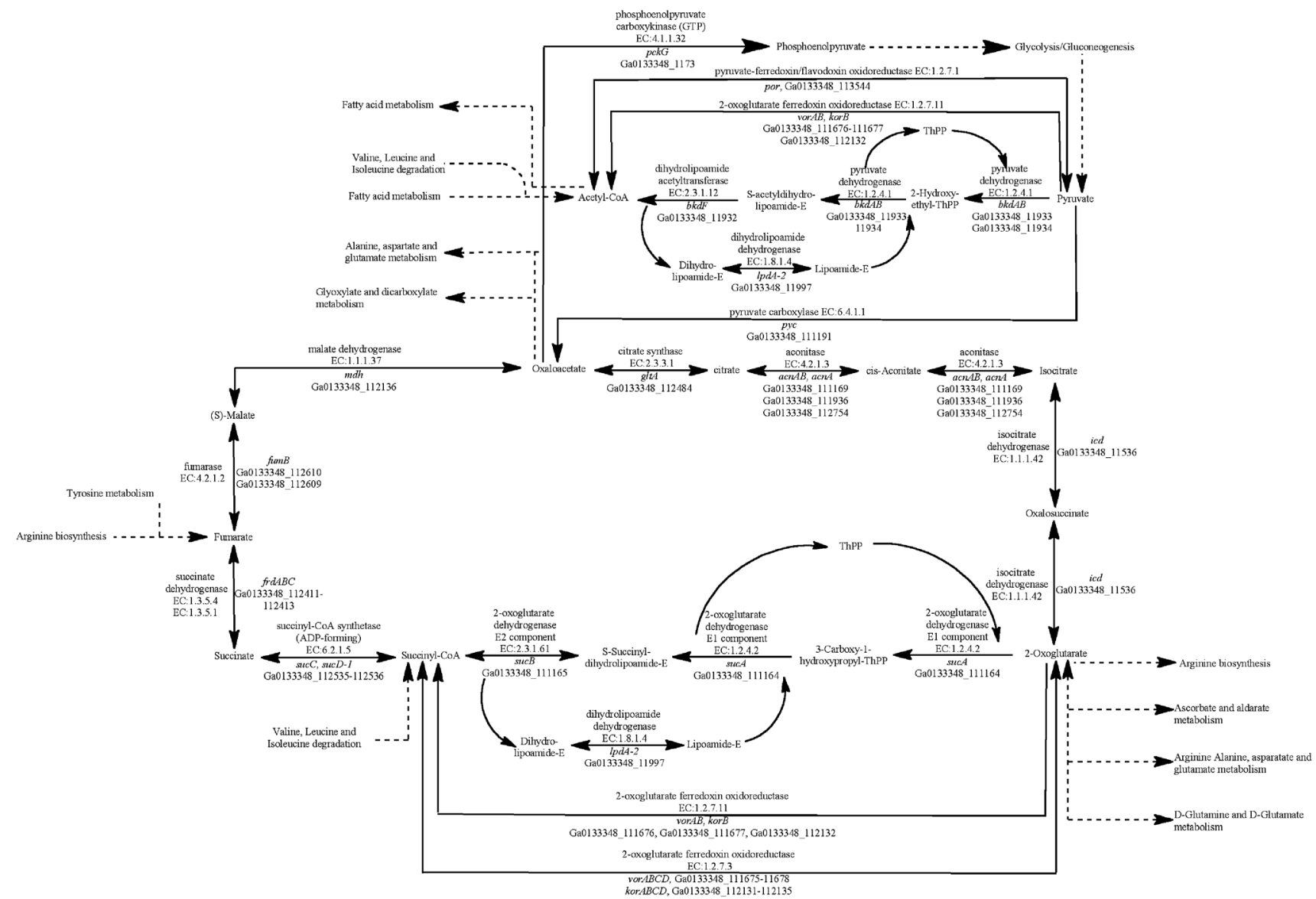

Fig. 1 Identification of genes that code for proteins from the tricarboxylic acid (TCA) cycle in the G. anodireducens SD-1 genome.

being critical for extracellular electron exchange by Geobacter have homologs in G. anodireducens (Table 3, ESI Table S2 $\dagger$ ).

In order for Geobacter to use extracellular substrates as terminal electron acceptors, they need to be able to transfer electrons from the quinone/quinol pool in the inner membrane, across the periplasm and then across the outer membrane to the extracellular environment. ${ }^{3,80}$ Two inner membrane $c$-type cytochromes in $G$. sulfurreducens, the inner membrane cytochrome $\mathrm{c}(\mathrm{ImcH})$ and a cytochrome protein with $b$ - and $c$-type domains (CbcL), appear to be involved in the early steps of

\section{G. sulfurreducens PCA}

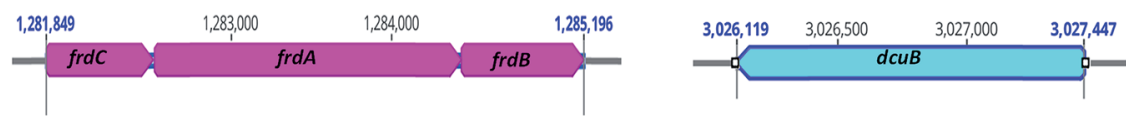

G. anodireducens SD-1

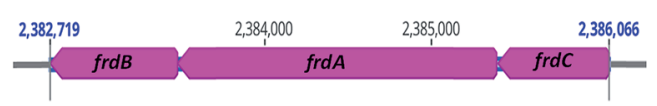

G. soli GSSO1

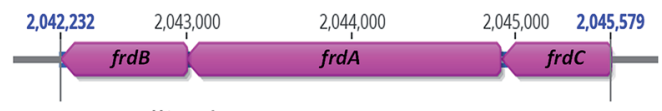

G. metallireducens GS-15

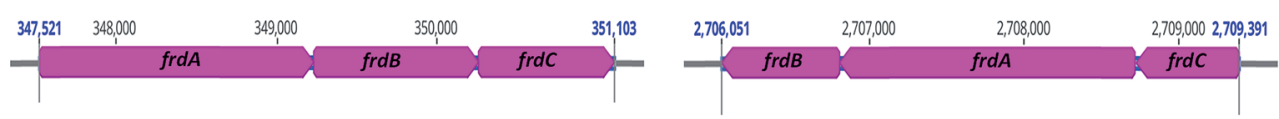

Fig. 2 Location of genes that code for fumarate reductase subunits (frdABC) in G. sulfurreducens PCA, G. anodireducens SD-1, G. soli GSS01, and G. metallireducens GS-15 genomes. G. sulfurreducens PCA is the only one of the four genomes that contains the gene that codes for the anaerobic C4-dicarboxylate transporter $(d c u B)$ and $G$. metallireducens is the only one of the four with two copies of the frdABC operon. 
Table 3 Homologs in G. anodireducens for genes from G. sulfurreducens and G. metallireducens that code for proteins that show impaired growth on extracellular electron acceptors when they are deleted from the chromosome

\begin{tabular}{|c|c|c|c|c|c|}
\hline Locus ID & SD-1 Locus ID & Abbreviation & Annotation & Impaired growth substrate(s) & References \\
\hline GSU1761 & Ga0133348_111806 & $\operatorname{pgcA}$ & Soluble extracellular cytochrome c, class I & Fe(III) oxide & 31 and 34 \\
\hline $\begin{array}{l}\text { GSU2724- } \\
\text { GSU2726 }\end{array}$ & No homologs & extEFG & Outer membrane electron conduit complex & Fe(III) citrate, & 88 \\
\hline $\begin{array}{l}\text { GSU2642- } \\
\text { GSU2645 }\end{array}$ & $\begin{array}{l}\text { Ga0133348_11946- } \\
11949\end{array}$ & $\operatorname{ext} A B C D$ & Porin-cytochrome (Pcc) complex & Anode & 88 \\
\hline $\begin{array}{l}\text { GSU2936- } \\
\text { GSU2940 }\end{array}$ & $\begin{array}{l}\text { Ga0133348_113069- } \\
113073\end{array}$ & extHIJKL & Porin-cytochrome (Pcc) complex & $\mathrm{Fe}(\mathrm{III})$ citrate, anode & 88 \\
\hline $\begin{array}{l}\text { GSU2731- } \\
\text { GSU2739 }\end{array}$ & $\begin{array}{l}\text { Ga0133348_11855- } \\
11861\end{array}$ & $\begin{array}{l}\text { omcBC } \\
\text { complex }\end{array}$ & Two tandem porin-cytochrome (Pcc) complexes & $\begin{array}{l}\mathrm{Fe}(\text { III) oxide, } \mathrm{Fe}(\text { III) citrate, } \\
\text { anode }\end{array}$ & $\begin{array}{l}85 \text { and } \\
87-91\end{array}$ \\
\hline GSU3259 & Ga0133348_113383 & $i m c H$ & Inner membrane c-type cytochrome protein & Fe(III) citrate, Mn(Iv) oxide & 82 \\
\hline GSU0274 & Ga0133348_11226 & $c b c L$ & $b / c$-type cytochrome domain protein & Fe(III) oxide & 83 \\
\hline GSU2504 & Ga0133348_111108 & omcS & Outer membrane $c$-type cytochrome & & 33 \\
\hline GSU2076 & Ga0133348_111435 & omcZ & Outer membrane $c$-type cytochrome & Anode & 37 and 38 \\
\hline GSU0618 & Ga0133348_11695 & omcE & Outer membrane $c$-type cytochrome & $\begin{array}{l}\text { Fe(III) oxide, Mn(Iv) oxide, } \\
\text { anode, AQDS }\end{array}$ & 32 and 33 \\
\hline GSU1496 & Ga0133348_112105 & pilA- $N$ & Pilin domain protein & Fe(III) oxide, anode & $\begin{array}{l}37,39 \text { and } \\
101\end{array}$ \\
\hline GSU0612 & Ga0133348_11688 & ppcA & Periplasmic cytochrome c, class III & $\mathrm{Fe}($ III) citrate & 35 and 84 \\
\hline GSU1394 & Ga0133348_112215 & ompB & Multicopper oxidase protein & Fe(III) oxide, Mn(Iv) oxide & 100 \\
\hline GSU2657 & No homolog & ompC & Multicopper oxidase protein & $\mathrm{Fe}($ III) oxide & 99 \\
\hline GSU1501 & Ga0133348_112101 & $x a p D$ & $\begin{array}{l}\text { ATP dependent transporter involved in } \\
\text { exopolysaccharide biosynthesis }\end{array}$ & Fe(III) oxide, anode & $\begin{array}{l}105 \text { and } \\
106\end{array}$ \\
\hline GSU1704 & Ga0133348_111888 & esnA & Mcp protein & Anode & 87 \\
\hline GSU2220 & Ga0133348_111374 & $\operatorname{esn} B$ & cheW scaffolding protein & Anode & 87 \\
\hline GSU2222 & Ga0133348_111372 & esnC & cheA histidine kinase & Anode & 87 \\
\hline GSU3376 & Ga0133348_1182 & esnD & Diguanylate cyclase & Anode & 87 \\
\hline Gmet_0557 & Ga0133348_113044 & omcP & Outer membrane c-type cytochrome & Fe(III) oxide & 32 and 35 \\
\hline Gmet_0558 & No homolog & omcO & Outer membrane c-type cytochrome & $\mathrm{Fe}($ III) oxide & 32 and 35 \\
\hline Gmet_1867 & Ga0133348_111778 & & $c$-type cytochrome & $\mathrm{Fe}($ III) oxide & 32 \\
\hline Gmet_1868 & Ga0133348_111777 & - & $c$-type cytochrome & $\mathrm{Fe}($ III) oxide & 32 \\
\hline GSU2505 & Ga0133348_111106 & - & NHL repeat domain protein & Anode & 105 \\
\hline GSU3361 & Ga0133348_1198 & - & Transglutaminase domain protein & Anode & 105 \\
\hline Gmet_2029 & Ga0133348_111539 & - & Exopolysaccharide biosynthesis protein & Fe(III) oxide & 32 \\
\hline
\end{tabular}

electron transfer to extracellular substrates. ${ }^{\mathbf{8 1 - 8 3}}$ ImcH is required for reduction of extracellular electron acceptors with reduction potentials greater than $0.1 \mathrm{~V}$ versus the standard hydrogen electrode (SHE) such as Fe(III) citrate and insoluble $\mathrm{Mn}$ (Iv) oxides, ${ }^{\mathbf{8}}$ while CbcL is important for electron transfer to low potential acceptors such as Fe(III) oxides. ${ }^{83}$ Homologs for both $i m c H$ and $c b c L$ are present in the G. anodireducens, G. soli, and G. metallireducens genomes (Table 3, ESI Table S2B $\dagger$ ). All four genomes also have homologs for PpcA, another periplasmic $c$-type cytochrome that is required for efficient reduction of $\mathrm{Fe}(\mathrm{III})$ citrate $^{\mathbf{8 4}}$ but not insoluble $\mathrm{Fe}(\mathrm{III})$-oxide or an electrode. $^{35}$

Once periplasmic and inner membrane cytochromes shuttle electrons across the periplasm, they need to then be transferred across the outer membrane. Studies have suggested that porin cytochrome (Pcc) protein complexes, found in all Geobacter species that have been sequenced to date, act as electron conduits for transfer across the outer membrane. ${ }^{\mathbf{8 5 , 8 6}}$ These conduits are composed of a periplasmic multiheme $c$-type cytochrome, a porin like outer membrane protein, and an outer membrane $c$-type cytochrome.$^{85,87-91}$ The G. sulfurreducens genome has 5 gene clusters that code for putative Pcc complexes; ombB-omaB-omcB (GSU2737-GSU2739), ombC-
omaC-omcC (GSU2731-GSU2733), extEFG (GSU2724-GSU2726), extABCD (GSU2642-GSU2645), and extHIJKL (GSU2936GSU2940), each of which appears to shuttle electrons to different acceptors. ${ }^{87,88}$ The G. anodireducens, G. soli, and $G$. metallireducens genomes have homologs for all of the pcc complexes found in G. sulfurreducens except extEFG (Table 3, ESI Table $\mathrm{S} 2 \mathrm{~B} \dagger$ ).

OmcB, which is part of the $o m b B-o m a B-o m c B$ complex in $G$. sulfurreducens, is localized to the exterior surface of the outer membrane ${ }^{92}$ and is thought to transfer electrons to extracellular multiheme $c$-type cytochromes that act as terminal reductases. ${ }^{3,85}$ There is no homolog for omcB in G. metallireducens, although another $c$-type cytochrome (Gmet_0910) is found in a syntenous location. ${ }^{24}$ However, deletion of this gene did not impair $\mathrm{Fe}(\mathrm{III})$ oxide reduction. ${ }^{32}$ Both $G$. anodireducens (Ga0133348_11857) and G. soli (Ga0077628_11353) have omcB homologs with $84.09 \%$ and $83.82 \%$ amino acid sequence identity to that of $G$. sulfurreducens.

There also appears to be a considerable amount of variation in terminal $c$-type cytochromes between species and even within the same species. In G. sulfurreducens, the multiheme outer membrane $c$-type cytochrome, OmcS, is required for reduction of $\mathrm{Fe}(\mathrm{III})-$ and $\mathrm{Mn}(\mathrm{IV})$ oxides, $^{33}$ the uptake of electrons during 
$\operatorname{DIET}^{79}$ and $\mathrm{Fe}(0),{ }^{77}$ and anodes operated in fuel cell mode with thin biofilms. ${ }^{36}$ Immunogold labeling has shown that OmcS can localize along electrically conductive pili found on the G. sulfurreducens surface, ${ }^{93}$ and recent studies have suggested that it can form cytochrome based conductive filaments. ${ }^{\mathbf{9 4 , 9 5}}$ OmcS also appears to be involved in electron transfer to insoluble $\mathrm{Fe}(\mathrm{III})$ oxide and anodes by G. soli. ${ }^{54}$ G. anodireducens also has a homolog for OmcS (Ga0133348_111108) with amino acid sequence identity of $95.16 \%$. However, omcS homologs are not present in genomes from G. metallireducens or most other Geobacter species (Table 3, ESI Table $\mathrm{S} 2 \dagger$ ). ${ }^{3}$

Although most species within the genus Geobacter do not have OmcS, they all produce extracellular multiheme $c$-type cytochromes that can serve as terminal reductases. For example, the multiheme $c$-type cytochrome GscA (Gbem_3371) found in $G$. bemidjiensis was able to restore $\mathrm{Fe}(\mathrm{III})$ oxide reduction in the OmcS-deficient strain of G. sulfurreducens. ${ }^{96}$ In addition, while OmcS is required for efficient electron transfer from G. sulfurreducens to $\mathrm{Fe}(\mathrm{III})$ oxide, ${ }^{33}$ and in the reverse direction from an electron-donating partner during DIET, ${ }^{79}$ another extracellular multiheme c-type cytochrome (Gmet_2896) is needed for DIET and Fe(III) reduction by $G$. metallireducens. ${ }^{32,40}$ The outer membrane multiheme $c$-type cytochromes OmcP (GSU2913) and OmcO (GSU2912) are also not required for reduction of Fe(III) oxide by G. sulfurreducens, ${ }^{35}$ but their homologs (Gmet_0557 and Gmet_0558) are required for $\mathrm{Fe}(\mathrm{III})$ oxide respiration by $G$. metallireducens. ${ }^{32} \mathrm{G}$. anodireducens has a homolog for omcP (Ga0133348_113044) and two homologs for omcO (Ga0133348_113042 and Ga0133348_113043).

PgcA (GSU1761) is another extracellular c-type cytochrome that plays a role in $\mathrm{Fe}(\mathrm{III})$ reduction in some strains of Geobacter but not others. ${ }^{31,34}$ It is a soluble $c$-type cytochrome that is secreted into the extracellular environment to facilitate Fe(III) reduction. ${ }^{31,34}$ G. uraniireducens also releases a soluble electron shuttle that promotes Fe(III) oxide reduction, ${ }^{97}$ however, this shuttle was never characterized. The G. uraniireducens genome contains a gene that codes for a PgcA homolog (Gura_0706) which could have served as the shuttle and was significantly expressed in cells grown in $\mathrm{Fe}(\mathrm{III})$ containing sediments. ${ }^{35,98}$ G. metallireducens does not have a PgcA homolog, however, homologs are found in both $G$. anodireducens (Ga0133348_111806) and G. soli (Ga0077628_111213) genomes (Table 3, ESI Table S2†).

Another multiheme outer surface $c$-type cytochrome, OmcZ, is required for electron transfer to anodes in flow-through systems with thick biofilms $(>50 \mu \mathrm{m}),{ }^{37}$ but not for reduction of anodes with thin biofilms, Fe(III)- or Mn(Iv) oxides by G. sulfurreducens. ${ }^{35,36}$ The homolog for omcZ in G. metallireducens (Gmet_0930) however, was essential for Fe(III) oxide reduction. ${ }^{32}$ Homologs for omcZ are found in all genomes analyzed in this study (Table 3, ESI Table S2†).

Other electron transport proteins that have been implicated in extracellular electron transfer from the G. sulfurreducens outer membrane include two outer membrane multicopper proteins (OmpB and $\mathrm{OmpC}$ ), ${ }^{\mathbf{9 9}, 100} \mathrm{OmcE},{ }^{33}$ and electrically conductive pili. ${ }^{101-103}$ All of the genomes have genes coding for OmcE and OmpB, but only the G. metallireducens genome has an ompC homolog (ESI Table S1 $\dagger$ ). A unique extracellular electron transfer component characteristic of Geobacter species is the presence of pilin monomers that have a structure that enables them to be electrically conductive..$^{30,101-103}$ Conductive PilA subunits have $>9 \%$ aromatic amino acid residues localized in specific regions along the protein and they do not have large gaps between the aromatic residues. ${ }^{29,30,104}$ Both the G. anodireducens and G. soli mature PilA monomers have $\mathbf{1 0 . 8 \%}$ aromatic amino acids and their largest gap is 22 amino acids, which is the same as both $G$. metallireducens and G. sulfurreducens. Therefore, the G. anodireducens and G. soli pili are likely to be conductive.

\subsection{Other proteins involved in extracellular electron transfer}

In addition to the involvement of electron transport proteins in reduction of extracellular acceptors, proteins involved in biofilm formation also appear to be important. For example, XapD (GSU1501), which is an ATP-dependent transporter that is encoded by a gene located within an operon with extracellular polysaccharide (xapABCDEFGH) biosynthesis genes, is required for reduction of anodes and Fe(III) oxide. ${ }^{\mathbf{1 0 5 , 1 0 6}} \mathrm{A}$ number of genes involved in extracellular polysaccharide biosynthesis were also more significantly transcribed by $G$. metallireducens cells grown with $\mathrm{Fe}(\mathrm{III})$ oxide provided as the electron acceptor than cells grown with Fe(III) citrate. ${ }^{32}$ In fact, deletion of Gmet_2029 which codes for a lipopolysaccharide biosynthesis chain length determinant protein completely inhibited Fe(III) oxide reduction by G. metallireducens. ${ }^{32}$ All four Geobacter genomes in this study had genes coding for both the XapD protein and Gmet_2029 (Table 3, ESI Table S2B $\dagger$ ).

Another series of proteins involved in electron transfer to poised anodes are part of an electrode sensing network (Esn) and include an MCP (EsnA, GSU1704), a CheW-like scaffolding protein (EsnB, GSU2220), a CheA-like histidine kinase (EsnC, GSU2222), and a diguanylate cyclase (EsnD, GSU3376).${ }^{87}$ It has been proposed that these Esn proteins regulate the accumulation of cyclic di-GMP, which is involved in biofilm formation. ${ }^{87,107,108}$ All of the genomes analyzed in this study have genes coding for all of the Esn proteins (Table 3, ESI Table S2B $\dagger$ ).

Other proteins implicated in electrode and/or $\mathrm{Fe}(\mathrm{III})$ reduction by $G$. sulfurreducens that are not considered electron transport proteins include an NHL repeat domain protein (GSU2505) located just downstream from the omcS gene that might be required for proper assembly and/or expression of OmcS, and a transglutaminase domain protein (GSU3361) likely involved in posttranslational modification of proteins involved in extracellular electron transport. ${ }^{105}$ All four genomes from this study have both of these genes (Table 3, ESI Table S2B $\dagger$ ).

\subsection{Proteins involved in stress responses and DNA repair}

One significant difference that was apparent when TIGR (The Institute for Genomic Research) categories were compared with the Function Category Comparison tool was that SD-1 has more genes coding for proteins involved in DNA replication, recombination and repair (143 genes compared to 86 in PCA, 94 in GS15, and 98 in SS01). Many DNA recombination and repair genes (uvrA, uvrD, recJ, recN, polA, priA, mutS, and pmbA) are duplicated 
in the genome (ESI Table S $3 \dagger$ ), which is a genome trait that is not observed in the other 3 Geobacter species. Additionally, out of the 130 putative open reading frames detected in the plasmid genome, 17 genes coded for proteins involved in DNA replication, recombination or repair (ESI Table S4 $\dagger$ ). These proteins included the DNA repair proteins RadC and MutS, DNA primase, an ATP-dependent helicase and DNA polymerase III and IV subunits. This redundancy in DNA repair genes might give $G$. anodireducens an upper edge in stressful conditions like high salt environments or on anode surfaces where protons accumulate and lower the $\mathrm{pH},{ }^{109}$ as increased levels of these proteins might allow cells to rapidly repair DNA damage.

The mechanosensitive ion channel (Msc) proteins are involved in protection from osmotic shock and are induced in response to high salt concentrations in some bacteria. ${ }^{\mathbf{1 1 0}}$ Six different genes coding for mechanosensitive ion channel proteins were found in the G. anodireducens (Ga0133348_112933, Ga0133348_111255, Ga0133348_111279, Ga0133348_111853， Ga0133348_111966, Ga0133348_112030), G. soli (Ga0077628_112329, Ga0077628_11701, Ga0077628_11719, Ga0077628_111256, Ga0077628_111444, Ga0077628_111502) and G. sulfurreducens (GSU2794, GSU1557, GSU1633, GSU1723, GSU2316, GSU2357) genomes compared to only three in the G. metallireducens genome (Gmet_2522, Gmet_1942, Gmet_2581), suggesting that these proteins might also help Geobacter survive osmotically stressful environments like those with elevated salt concentrations.

Studies have also shown that many other stress response genes including oxidative stress, heat shock, and universal stress genes are more significantly expressed on anode surfaces and when Fe(III) serves as an electron acceptor. ${ }^{\mathbf{9 8 , 1 1 1 , 1 1 2}}$ Analysis of other stress response genes (i.e. oxidative stress, heat shock proteins, and universal stress proteins) did not reveal any apparent differences among the four Geobacter species (ESI Table S3†).

\section{Conclusions}

G. anodireducens is a recently isolated Geobacter species that could be used for practical applications due to its generation of high current densities and its ability to withstand high salt concentrations in BESs. The genome of G. anodireducens was compared to G. sulfurreducens PCA, G. metallireducens GS-15, and $G$. soli GSS01 in order to uncover potential traits that give SD-1 its superior exoelectrogenic capabilities. The analysis identified many genes likely involved with EET including 87 genes encoding for $c$-type cytochromes, many of which are homologous to those previously found to be essential for EET in other Geobacter species. In addition, G. anodireducens has substantially more genes for DNA repair and osmotic shock protection than other Geobacter species, likely explaining its ability to survive in the stressful environment found in high salt BES. This study provides an instrumental foundation for future molecular and biochemical analyses of this strain.

\section{Conflicts of interest}

There are no conflicts of interest to declare.

\section{Acknowledgements}

This research was supported by the Zhejiang Provincial Natural Science Foundation of China (Grant No. LY17D060004), the National Natural Science Foundation of China (Grant No. 51408541), and Joint Zhoushan City and Zhejiang University Cooperation Project (Grant No. 2017C82224).

\section{References}

1 D. R. Lovley, D. E. Holmes and K. P. Nevin, Adv. Microb. Physiol., 2004, 49, 219-286.

2 D. R. Lovley, Annu. Rev. Microbiol., 2017, 71, 643-664.

3 D. R. Lovley, T. Ueki, T. Zhang, N. S. Malvankar, P. M. Shrestha, K. A. Flanagan, M. Aklujkar, J. E. Butler, L. Giloteaux and A.-E. Rotaru, in Adv. Microb. Physiol., Elsevier, 2011, vol. 59, pp. 1-100.

4 H. Liu, S. Grot and B. E. Logan, Environ. Sci. Technol., 2005, 39, 4317-4320.

5 X. Cao, X. Huang, P. Liang, K. Xiao, Y. Zhou, X. Zhang and B. E. Logan, Environ. Sci. Technol., 2009, 43, 7148-7152.

6 K. P. Nevin, T. L. Woodard, A. E. Franks, Z. M. Summers and D. R. Lovley, mBio, 2010, 1, e00103-e00110.

7 B. H. Kim, I. S. Chang, G. C. Gil, H. S. Park and H. J. Kim, Biotechnol. Lett., 2003, 25, 541-545.

8 N. E. Stein, K. J. Keesman, H. V. Hamelers and G. van Straten, Biosens. Bioelectron., 2011, 26, 3115-3120.

9 D. P. Webster, M. A. TerAvest, D. F. Doud, A. Chakravorty, E. C. Holmes, C. M. Radens, S. Sureka, J. A. Gralnick and L. T. Angenent, Biosens. Bioelectron., 2014, 62, 320-324.

10 R. D. Cusick, B. Bryan, D. S. Parker, M. D. Merrill, M. Mehanna, P. D. Kiely, G. Liu and B. E. Logan, Appl. Microbiol. Biotechnol., 2011, 89, 2053-2063.

11 D. R. Lovley, Annu. Rev. Microbiol., 2012, 66, 391-409.

12 S. M. Strycharz-Glaven, R. M. Snider, A. Guiseppi-Elie and L. M. Tender, Energy Environ. Sci., 2011, 4, 4366-4379.

13 N. S. Malvankar, M. T. Tuominen and D. R. Lovley, Energy Environ. Sci., 2012, 5, 8651-8659.

14 L. Shi, H. Dong, G. Reguera, H. Beyenal, A. Lu, J. Liu, H.-Q. Yu and J. K. Fredrickson, Nat. Rev. Microbiol., 2016, 14, 651.

15 M. Breuer, K. M. Rosso, J. Blumberger and J. N. Butt, J. R. Soc., Interface, 2015, 12, 20141117.

16 D. Coursolle, D. B. Baron, D. R. Bond and J. A. Gralnick, J. Bacteriol., 2010, 192, 467-474.

17 E. Marsili, J. B. Rollefson, D. B. Baron, R. M. Hozalski and D. R. Bond, Appl. Environ. Microbiol., 2008, 74, 7329-7337.

18 N. J. Kotloski and J. A. Gralnick, mBio, 2013, 4, e00553-12. 19 K. Dolch, J. Danzer, T. Kabbeck, B. Bierer, J. Erben, A. H. Förster, J. Maisch, P. Nick, S. Kerzenmacher and J. Gescher, Bioresour. Technol., 2014, 157, 284-292.

20 C. E. A. Engel, F. Schattenberg, K. Dohnt, U. Schröder, S. Müller and R. Krull, Frontiers in Bioengineering and Biotechnology, 2019, 7, 60.

21 B. Methe, K. E. Nelson, J. A. Eisen, I. T. Paulsen, W. Nelson, J. Heidelberg, D. Wu, M. Wu, N. Ward and M. Beanan, Scicence, 2003, 302, 1967-1969. 
22 M. V. Coppi, C. Leang, S. J. Sandler and D. R. Lovley, Appl. Environ. Microbiol., 2001, 67, 3180-3187.

23 A.-E. Rotaru, T. L. Woodard, K. P. Nevin and D. R. Lovley, Frontiers in Microbiology, 2015, 6, 744.

24 M. Aklujkar, J. Krushkal, G. DiBartolo, A. Lapidus, M. L. Land and D. R. Lovley, BMC Microbiol., 2009, 9, 109.

25 F. Caccavo, D. J. Lonergan, D. R. Lovley, M. Davis, J. F. Stolz and M. J. McInerney, Appl. Environ. Microbiol., 1994, 60, 3752-3759.

26 D. Sun, A. Wang, S. Cheng, M. Yates and B. E. Logan, Int. J. Syst. Evol. Microbiol., 2014, 64, 3485-3491.

27 S. Zhou, G. Yang, Q. Lu and M. Wu, Int. J. Syst. Evol. Microbiol., 2014, 64, 3786-3791.

28 J. E. Butler, N. D. Young and D. R. Lovley, BMC Genomics, 2010, 11, 40.

29 D. E. Holmes, Y. Dang, D. J. Walker and D. R. Lovley, Microb. Genomics, 2016, 2, e000072.

30 D. R. Lovley, Curr. Opin. Electrochem., 2017, 4, 190-198.

31 J. A. Smith, P.-L. Tremblay, P. M. Shrestha, O. L. Snoeyenbos-West, A. E. Franks, K. P. Nevin and D. R. Lovley, Appl. Environ. Microbiol., 2014, 80, 4331-4340.

32 J. A. Smith, D. R. Lovley and P.-L. Tremblay, Appl. Environ. Microbiol., 2013, 79, 901-907.

33 T. Mehta, M. V. Coppi, S. E. Childers and D. R. Lovley, Appl. Environ. Microbiol., 2005, 71, 8634-8641.

34 L. A. Zacharoff, D. J. Morrone and D. R. Bond, Frontiers in Microbiology, 2017, 8, 2481.

35 M. Aklujkar, M. Coppi, C. Leang, B. Kim, M. Chavan, L. Perpetua, L. Giloteaux, A. Liu and D. Holmes, Microbiology, 2013, 159, 515-535.

36 D. E. Holmes, S. K. Chaudhuri, K. P. Nevin, T. Mehta, B. A. Methé, A. Liu, J. E. Ward, T. L. Woodard, J. Webster and D. R. Lovley, Environ. Microbiol., 2006, 8, 1805-1815.

37 K. P. Nevin, B.-C. Kim, R. H. Glaven, J. P. Johnson, T. L. Woodard, B. A. Methé, R. J. DiDonato Jr, S. F. Covalla, A. E. Franks and A. Liu, PLoS One, 2009, 4, e5628.

38 K. Inoue, X. Qian, L. Morgado, B.-C. Kim, T. Mester, M. Izallalen, C. A. Salgueiro and D. R. Lovley, Appl. Environ. Microbiol., 2010, 76, 3999-4007.

39 P. L. Tremblay, M. Aklujkar, C. Leang, K. P. Nevin and D. Lovley, Environ. Microbiol. Rep., 2012, 4, 82-88.

40 P. M. Shrestha, A.-E. Rotaru, Z. M. Summers, M. Shrestha, F. Liu and D. R. Lovley, Appl. Environ. Microbiol., 2013, 79, 2397-2404.

41 K. P. Nevin, D. E. Holmes, T. L. Woodard, E. S. Hinlein, D. W. Ostendorf and D. R. Lovley, Int. J. Syst. Evol. Microbiol., 2005, 55, 1667-1674.

42 D. Sun, D. Call, A. Wang, S. Cheng and B. E. Logan, Environ. Microbiol. Rep., 2014, 6, 723-729.

43 D. F. Call, R. C. Wagner and B. E. Logan, Appl. Environ. Microbiol., 2009, 75, 7579-7587.

44 D. F. Call and B. E. Logan, Biosens. Bioelectron., 2011, 26, 4526-4531.

45 E. J. Phillips and D. R. Lovley, Soil Sci. Soc. Am. J., 1987, 51, 938-941.
46 R. K. Aziz, D. Bartels, A. A. Best, M. DeJongh, T. Disz, R. A. Edwards, K. Formsma, S. Gerdes, E. M. Glass, M. Kubal, F. Meyer, G. J. Olsen, R. Olson, A. L. Osterman, R. A. Overbeek, L. K. McNeil, D. Paarmann, T. Paczian, B. Parrello, G. D. Pusch, C. Reich, R. Stevens, O. Vassieva, V. Vonstein, A. Wilke and O. Zagnitko, BMC Genomics, 2008, 9, 75.

47 T. N. Petersen, S. Brunak, G. von Heijne and H. Nielsen, Nat. Methods, 2011, 8, 785.

48 A. Krogh, B. Larsson, G. von Heijne and E. L. L. Sonnhammer, J. Mol. Biol., 2001, 305, 567-580.

49 Y. Moriya, M. Itoh, S. Okuda, A. C. Yoshizawa and M. Kanehisa, Nucleic Acids Res., 2007, 35, 182-185.

50 S. F. Altschul, T. L. Madden, A. A. Schäffer, J. Zhang, Z. Zhang, W. Miller and D. J. Lipman, Nucleic Acids Res., 1997, 25, 3389-3402.

51 C. Camacho, G. Coulouris, V. Avagyan, N. Ma, J. Papadopoulos, K. Bealer and T. L. Madden, BMC Bioinf., 2009, 10, 421.

52 D. Sun, D. F. Call, P. D. Kiely, A. Wang and B. E. Logan, Biotechnol. Bioeng., 2012, 109, 405-414.

53 D. R. Lovley, S. J. Giovannoni, D. C. White, J. E. Champine, E. Phillips, Y. A. Gorby and S. Goodwin, Arch. Microbiol., 1993, 159, 336-344.

54 X. Cai, L. Huang, G. Yang, Z. Yu, J. Wen and S. Zhou, Frontiers in Microbiology, 2018, 9, 1075.

55 M. Miyahara, A. Kouzuma and K. Watanabe, AMB Express, 2015, 5, 34.

56 B. E. Logan and K. Rabaey, Science, 2012, 337, 686-690.

57 D. R. Lovley, Energy Environ. Sci., 2011, 4, 4896-4906.

58 A. Y. Mulkidjanian, M. Y. Galperin, K. S. Makarova, Y. I. Wolf and E. V. Koonin, Biol. Direct, 2008, 3, 13.

59 R. A. Capaldi and R. Aggeler, Trends Biochem. Sci., 2002, 27, 154-160.

60 V. Kabaleeswaran, N. Puri, J. E. Walker, A. G. Leslie and D. M. Mueller, EMBO J., 2006, 25, 5433-5442.

61 V. Müller and G. Grüber, Cell. Mol. Life Sci., 2003, 60, 474494.

62 Ü. Coskun, Y. L. Chaban, A. Lingl, V. Müller, W. Keegstra, E. J. Boekema and G. Grüber, J. Biol. Chem., 2004, 279, 38644-38648.

63 M. Nakanishi-Matsui and M. Futai, IUBMB Life, 2006, 58, 318-322.

64 M. Ito, M. Morino and T. A. Krulwich, Frontiers in Microbiology, 2017, 8, 2325.

65 T. A. Krulwich, G. Sachs and E. Padan, Nat. Rev. Microbiol., 2011, 9, 330.

66 E. Padan, E. Bibi, M. Ito and T. A. Krulwich, Biochim. Biophys. Acta, Biomembr., 2005, 1717, 67-88.

67 D. G. Fuster and R. T. Alexander, Pflügers Archiv: European Journal of Physiology, 2014, 466, 61-76.

68 E. Padan and M. Landau, in The Alkali Metal Ions: Their Role for Life, Springer, 2016, pp. 391-458.

69 T. Zhang, T. S. Bain, K. P. Nevin, M. A. Barlett and D. R. Lovley, Appl. Environ. Microbiol., 2012, 78, 8304-8310.

70 J. E. Butler, Q. He, K. P. Nevin, Z. He, J. Zhou and D. R. Lovley, BMC Genomics, 2007, 8, 180. 
71 T. Zhang, P.-L. Tremblay, A. K. Chaurasia, J. A. Smith, T. S. Bain and D. R. Lovley, Appl. Environ. Microbiol., 2013, 79, 7800-7806.

72 M. Carmona, M. T. Zamarro, B. Blázquez, G. DuranteRodríguez, J. F. Juárez, J. A. Valderrama, M. J. Barragán, J. L. García and E. Díaz, Microbiol. Mol. Biol. Rev., 2009, 73, 71-133.

73 S. Six, S. C. Andrews, R. E. Roberts, G. Unden and J. R. Guest, Biochem. Soc. Trans., 1993, 342S.

74 N. Nógrády, A. Imre, I. Rychlik, P. A. Barrow and B. Nagy, Vet. Microbiol., 2003, 97, 191-199.

75 R. Ullmann, R. Gross, J. Simon, G. Unden and A. Kröger, J. Bacteriol., 2000, 182, 5757-5764.

76 J. E. Butler, R. H. Glaven, A. Esteve-Núnez, C. Núnez, E. S. Shelobolina, D. R. Bond and D. R. Lovley, J. Bacteriol., 2006, 188, 450-455.

77 H.-Y. Tang, D. E. Holmes, T. Ueki, P. A. Palacios and D. R. Lovley, mBio, 2019, 10, e00303-e00319.

78 J. A. Smith, K. P. Nevin and D. R. Lovley, Frontiers in Microbiology, 2015, 6, 121.

79 Z. M. Summers, H. E. Fogarty, C. Leang, A. E. Franks, N. S. Malvankar and D. R. Lovley, Scicence, 2010, 330, 1413-1415.

80 L. Shi, T. C. Squier, J. M. Zachara and J. K. Fredrickson, Mol. Microbiol., 2007, 65, 12-20.

81 C. E. Levar, C. L. Hoffman, A. J. Dunshee, B. M. Toner and D. R. Bond, ISME J., 2017, 11, 741.

82 C. E. Levar, C. H. Chan, M. G. Mehta-Kolte and D. R. Bond, mBio, 2014, 5, e02034.

83 L. Zacharoff, C. H. Chan and D. R. Bond, Bioelectrochemistry, 2016, 107, 7-13.

84 J. R. Lloyd, C. Leang, A. L. H. Myerson, M. V. Coppi, S. Cuifo, B. Methe, S. J. Sandler and D. R. Lovley, Biochem. J., 2003, 369, 153-161.

85 Y. Liu, Z. Wang, J. Liu, C. Levar, M. J. Edwards, J. T. Babauta, D. W. Kennedy, Z. Shi, H. Beyenal and D. R. Bond, Environ. Microbiol. Rep., 2014, 6, 776-785.

86 L. Shi, J. K. Fredrickson and J. M. Zachara, Frontiers in Microbiology, 2014, 5, 657.

87 C. H. Chan, C. E. Levar, F. Jiménez-Otero and D. R. Bond, J. Bacteriol., 2017, 199, e00340-17.

88 F. J. Otero, C. H. Chan and D. R. Bond, J. Bacteriol., 2018, 200, e00347-18.

89 Y. Liu, J. K. Fredrickson, J. M. Zachara and L. Shi, Frontiers in Microbiology, 2015, 6, 1075.

90 C. Leang, M. V. Coppi and D. Lovley, J. Bacteriol., 2003, 185, 2096-2103.

91 C. Leang and D. R. Lovley, Microbiology, 2005, 151, 17611767.

92 X. Qian, G. Reguera, T. Mester and D. R. Lovley, FEMS Microbiol. Lett., 2007, 277, 21-27.
93 C. Leang, X. Qian, T. Mester and D. R. Lovley, Appl. Environ. Microbiol., 2010, 76, 4080-4084.

94 D. J. Filman, S. F. Marino, J. E. Ward, L. Yang, Z. Mester, E. Bullitt, D. R. Lovley and M. Strauss, bioRxiv, 2018, 492645.

95 F. Wang, Y. Gu, J. P. O'Brien, M. Y. Sophia, S. E. Yalcin, V. Srikanth, C. Shen, D. Vu, N. L. Ing and A. I. Hochbaum, Cell, 2019, 177, 361-369.

96 J. Yun, N. S. Malvankar, T. Ueki and D. R. Lovley, ISME J., 2016, 10, 310-320.

97 Y. Tan, R. Y. Adhikari, N. S. Malvankar, J. E. Ward, K. P. Nevin, T. L. Woodard, J. A. Smith, O. L. SnoeyenbosWest, A. E. Franks and M. T. Tuominen, Frontiers in Microbiology, 2016, 7, 980.

98 D. E. Holmes, R. A. O'neil, M. A. Chavan, L. A. N'guessan, H. A. Vrionis, L. A. Perpetua, M. J. Larrahondo, R. DiDonato, A. Liu and D. R. Lovley, ISME J., 2009, 3, 216. 99 D. E. Holmes, T. Mester, R. A. O'Neil, L. A. Perpetua, M. J. Larrahondo, R. Glaven, M. L. Sharma, J. E. Ward, K. P. Nevin and D. R. Lovley, Microbiology, 2008, 154, 1422-1435.

100 T. Mehta, S. E. Childers, R. Glaven, D. R. Lovley and T. Mester, Microbiology, 2006, 152, 2257-2264.

101 G. Reguera, K. D. McCarthy, T. Mehta, J. S. Nicoll, M. T. Tuominen and D. R. Lovley, Nature, 2005, 435, 1098-1101.

102 N. S. Malvankar, M. Vargas, K. P. Nevin, A. E. Franks, C. Leang, B.-C. Kim, K. Inoue, T. Mester, S. F. Covalla and J. P. Johnson, Nat. Nanotechnol., 2011, 6, 573-579.

103 M. Vargas, N. S. Malvankar, P.-L. Tremblay, C. Leang, J. A. Smith, P. Patel, O. Synoeyenbos-West, K. P. Nevin and D. R. Lovley, mBio, 2013, 4, e00105-e00113.

104 D. J. Walker, R. Y. Adhikari, D. E. Holmes, J. E. Ward, T. L. Woodard, K. P. Nevin and D. R. Lovley, ISME J., 2018, 12, 48.

105 J. B. Rollefson, C. E. Levar and D. R. Bond, J. Bacteriol., 2009, 191, 4207-4217.

106 J. B. Rollefson, C. S. Stephen, M. Tien and D. R. Bond, J. Bacteriol., 2011, 193, 1023-1033.

107 Z. F. Hallberg, X. C. Wang, T. A. Wright, B. Nan, O. Ad, J. Yeo and M. C. Hammond, Proc. Natl. Acad. Sci. U. S. A., 2016, 113, 1790-1795.

108 M. Valentini and A. Filloux, J. Biol. Chem., 2016, 291, 1254712555.

109 A. E. Franks, K. P. Nevin, H. Jia, M. Izallalen, T. L. Woodard and D. R. Lovley, Energy Environ. Sci., 2009, 2, 113-119.

110 E. S. Haswell, R. Phillips and D. C. Rees, Structure, 2011, 19, 1356-1369.

111 A. E. Franks, K. P. Nevin, R. H. Glaven and D. R. Lovley, ISME J., 2010, 4, 509-519.

112 P. J. Mouser, D. E. Holmes, L. A. Perpetua, R. DiDonato, B. Postier, A. Liu and D. R. Lovley, ISME J., 2009, 3, 454-465. 